\title{
EXPLORACIÓN DEL SUJETO Y PROCESO AUTOBIOGRÁFICO EN LA POESÍA DE MARTA ROJAS
}

\author{
Jorge Chen Sham
}

\begin{abstract}
RESUMEN
Este poemario de Marta Rojas nos introduce en los problemas que plantea la escritura femenina compemporánea, la búsqueda y la construcción de una identidad a partir de un proceso autobiográfico caracterizado por la renuncia de sí y la apertura hacia el mundo.
\end{abstract}

\begin{abstract}
These poems by Marta Rojas serve as an introduction to the problems presented in contemporary female writings: the search and construction of an identity through an autobiographic process characterized by redemption of oneself and an opening to the world.
\end{abstract}

Marta Eugenia Rojas ${ }^{1}$ es una de las más recientes voces que en la lírica femenina costarricense irrumpe con una escritura centrada, precisamente, en ese drama de la identidad característico de la producción autobiográfica femenina. En ese sentido, la búsqueda del sujeto se formula, ante todo, como una búsqueda de un nuevo lenguaje para acercarse a su cuerpo y para definir los deseos y las necesidades, por lo cual la escritura femenina se vuelca hacia la producción de una nueva intersubjetividad capaz de re-modelar y re-interpretar a la mujer. El primer poemario de Marta Rojas, La sonrisa de Penélope y su costumbre del adiós, publicado por la Editorial de la Universidad de Costa Rica en 1993, destaca, en primer lugar, por esa ausencia de un tono declarativo y expositivo, de manera que sitúa la comunicación en el ámbito de lo íntimo y del repliegue sobre sí mismo, propios de un hablante lírico que escudriña su experiencia personal (Chen 1994: 26-7). Aquí cabe enunciar lo que el poeta León Felipe proclama en su búsqueda iniciática para acercarnos a su condición de hombre interpelado por la palabra poética:

Quiero decir quién soy para que tú me respondas quién eres.

Quiero decir lo que soy para afirmar lo que he sido y para prepararme a lo que he de venir a ser (1982: 105). 
Esta proclama de León Felipe en el poema "Quisiera decir cómo me llamo", cobra plena vigencia en el ámbito del discurso lírico femenino actual, en la medida en que la vocación del poeta se afianza cuando emerge esa preocupación por conocerse a sí mismo, de ponerse en situación, con el fin de saber lo que pasa en el interior de su conciencia (cfr. Foucault 1991: 5072). Y al tematizarse el poeta en su recorrido biográfico dentro del proceso de comunicación de la lírica, comienza, gracias a la escritura, una incesante indagación de la identidad (Aranguren 1989: 20 y Peña-Marín 1989: 80-1). Sin embargo este proceso de indagación no es multidireccional, posee un foco de atracción como veremos. En este sentido, el recorrido autobiográfico, que proponemos aquí, se canaliza a partir de lo que es el yo lírico en el presente con las valoraciones que haga de sí mismo; por esta razón, el sujeto autobiográfico tratará de valorar su experiencia personal por lo que es hoy (Starobinski 1974: 66-7). Es la conciencia del presente la que moldea la percepción del pasado, por lo cual La sonrisa de Penélope se transforma en una autointerpretación recapituladora que fusiona la distancia temporal y espacial y neutraliza, por esta misma fuerza ilocutiva, estas divergencias en un solo sujeto, integrado así a partir de un punto de vista estético y creativo como diría Bajtin (1982: 133). Precisamente esta fusión recapituladora es la que sostiene la reivindicación afirmativa en el poema "Soy mujer", en donde la toma de conciencia se manifiesta, en efecto, en el acto de terminar con una "idea" de mujer que los otros han intentado incrustar y que ahora el hablante lírico rechaza como una imposición:

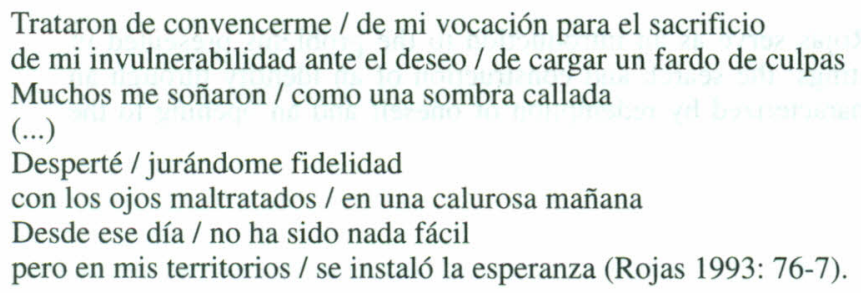

A la luz de lo anterior, llama poderosamente la atención que el sujeto lírico, en $L a$ sonrisa de Penélope, se situé con esa posesión de la esperanza de la que nos habla en el poema anterior, en la apremiante necesidad de seguir comprendiéndose a sí misma, pues como el poema manifiesta en su perfecit, en su cierre, la ordenación valorativa de su experiencia, a la cual hemos asistido los lectores a lo largo y a lo ancho del texto, tiene un valor de apertura. Así, la exploración se inscribe en el marco de la tentativa "de quien está explorando el significado de su biografía personal" (Navajas 1993: 125-6); por esa razón, el último poema, "Me consagro a la conquista", irrumpe anunciando la determinación de iniciar una empresa que conducirá al sujeto a la re-modelación de la vida misma en todas sus manifestaciones, de ahí que enfatice el hecho de que se trata de una vocación hacia la vida a la que ha sido interpelada gracias a la recapitulación autobiográfica realizada:

(...) Me consagro a la conquista / de la esperanza y de la fecundidad

Me consagro a descifrar el abecedario / los signos yuxtapuestos

y la sintaxis de los recodos (107).

Y esta acción de ganar nuevos territorios se hace bajo el signo de lo auténtico y circundante al sujeto, pues apela a una cotidianeidad construida a partir de lo telúrico y de la fertilidad de los frutos de la tierra: 
Busco la señal que me indique / la ruta del sembradío con olor a miel con follaje verde y fresco / con enredaderas y flores silvestres (107).

En este sentido, la empresa de "conquista", a la cual el hablante lírico se consagra, propone el fin de su búsqueda en términos de una cosecha. Por eso, la imagen de la tierra surge al final del poemario para insistir en el descubrimiento de una conciencia crítica que, lejos de mostrarse pesimista, reafirma su virtualidad de "tierra" fértil y la proyección telúrica de un sujeto femenino que busca ante todo autenticidad y se vive como una tentativa esperanzadora:

La cosecha / se regocijará

en el canto jubiloso / de mi eco (107).

Bajo una retórica auroral que anuncia el despertar del yo, nos abrimos hacia la posibilidad de comunicarse con los otros, hacia una identidad que, en forma vigorosa y exultante, se rebela en el despliegue de la relación con los otros, después de superar su exilio interior (Amoretti 1995), en el que el refugio en la intimidad y la renuncia solitaria que éste provoca conducen hacia la asunción de su condición de mujer².

A la luz de lo anterior, el sujeto femenino nos ofrece una perspectiva más genuina y auténtica en la medida en que la comunicación lírica no se establece en función de un apriori omnisciente y perfectivo, sino que se va moldeando gracias a una vulnerabilidad que permite darle profundidad y autenticidad a sus revelaciones y deseos. Y en este decurso, el poemario se centra en el hito que sirve de catalizador a este tejido de vivencias; se trata de la experiencia amorosa, con la cual se propone abrir un camino expedito hacia su intimidad. Es ahí donde, como decía San Agustín, el hombre se reflexiona a sí mismo encontrando su verdad: "In interiore homine habitat veritas" (citado por Aranguren 1989: 20); una verdad que la experiencia con el otro desencadena dolorosa pero catárticamente.

Por eso, priva en el poemario un encuentro con un tú masculino que conduce al sujeto femenino a descubrir los contornos y los límites del placer, tal y como lo encontramos en poemas de la primera y segunda secciones. Resaltan aquí poemas en donde se dramatiza toda una retórica del arte amatorio, en donde la mujer es "botella" y "copa" que debe, hasta la saciedad, colmarse en las manos y con la fuerza del amante:

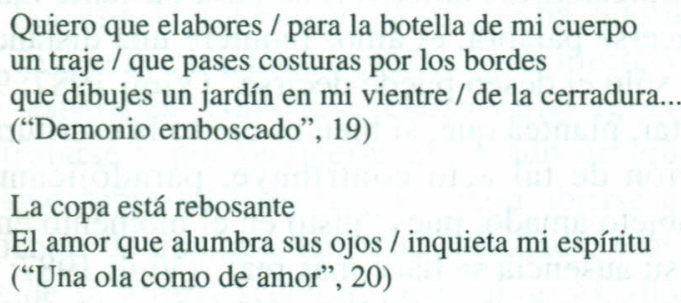

Así, el encuentro amoroso se transforma en un acto pletórico para la fertilidad de los cuerpos y de los deseos, por lo que en recíproca iniciativa, nos encontramos con un yo femenino desinhibido que también sabe asumir un papel activo y despierta el deseo de su amante moldéandolo como si fuera un "cántaro" al unísono crepitante de cuerpos que trasuntan tierra y se exploran inédita y auténticamente: 


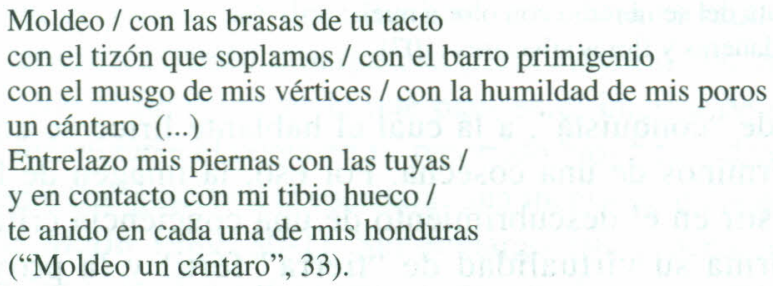

Al mismo tiempo, este sujeto femenino es capaz, gracias a la unión amorosa, de revelarnos su deseo materializado en el desenfreno del tacto, del gusto y del olfato, ya que, y en esto existe una gran coincidencia con gran parte de la literatura femenina contemporánea, el descubrimiento de la identidad está mediatizado por una asunción del cuerpo y una exploración de su lenguaje (cfr. Chen 1996: 35-6); al respecto Antonio Blanch agrega: "Puesto que el cuerpo humano es la principal mediación del deseo amoroso, la relación entre erotismo y expresión corporal es fundamental. El cuerpo (...) es la gran metáfora del hombre, es decir, el mejor medio de que dispone para comunicar su intimidad (y su deseo)" (1978: 479).

Cabe destacar que en la consonancia con el otro, se perfila la búsqueda de identidad en el hablante lírico, pues la ausencia del amado desencadena la reconstrucción de ese espacio compartido, valorado positivamente pero que ya no existe; de este modo, en el poema “CCómo?" la separación de los amantes se percibe como un desgarramiento que solo el tiempo logrará tal vez sanar:

Es tan difícil / la costumbre de tu ausencia caminar por estas calles / repasando tristemente

la dulzura de tu fuerza / tu ternura, mi pan

la caparazón que en el abrazo estrecho ablandamos (44).

Sin embargo, la ausencia del amado genera también la indagación biográfica del sujeto, quien afronta con entereza su situación de soledad, de manera que la "partida" se ve como carencia a la completud y a la felicidad anteriores. Desde esta perspectiva, no hay duda de que el sujeto femenino reconstruye lo vivido a partir de la ausencia del amado, por lo cual la situación comunicativa de La sonrisa de Penélope presupone que la escritura se pueda transformar en un acto de restauración de la memoria y de la ausencia del otro, porque, en este contexto, "el amor, o mejor dicho la expresión del amor (...) se basa bastante más sobre la ausencia que sobre la presencia. Para hacerse palabra, el amor requiere una distancia, una ausencia: la felicidad no se cuenta, se vive; sólo el deseo puede decirse" (Violi 1987: 97). Por otro, Patrizia Violi, a quien acabamos de citar, plantea que, si bien es cierto la escritura evoca para hacer presente al otro, la enunciación de tal acto contribuye, paradójicamente, a acrecentar la distancia entre el sujeto y el objeto amado, pues "justo en el momento en que se lo evoca, el otro parece alejarse aún más y su ausencia se hace más real" (Violi 1987: 97). Es lo que sucede en los poemas de la tercera sección "Pedías olvido", en donde aquí y allá busca el hablante la presencia del amado en aquel territorio compartido y trabajado en la efusión amorosa:

Te busqué como sentimiento sin rostro como anhelo sin tiempo / como refugio sin techo $\mathrm{y}$ te encuentro / pasajero sin equipaje 
En la tersura de mis manos / te palpo y contengo, arremolinados, / temores rebeliones / ansias ("Las trampas de la vida", 40).

La dialéctica amorosa del encuentro por la escritura es fugaz y pasajero y eso lo sabe el hablante lírico, quien no duda en lamentar la inevitable renuncia que debe producirse, ya que marca su fascinación por la despedida; "la costumbre del adiós" implica el volver a empezar y hacer memoria de una historia común:

Cuando recuerdo nuestro primer baile

la alegría transpirada / y tu roce con atuendos de erupción

Cuando se empaña el espejo de fiesta

y me asustan aires parduzcos y tiempos fúnebres

Cuando me sueño / acogida en tu casa

¡Cómo quisiera renunciar

a la costumbre / del adiós ("La costumbre del adiós", 41).

Por otra parte, gracias a la escritura, que le permite al sujeto problematizarse como tal, el yo re-examina su historia de amor y trae del olvido al amado, haciendo memoria de él, en una celebración que provoca, de rebote, el insondable dolor de la anagnórisis después del autoexamen. En este sentido, según Herbert Marcuse, "(1)a liberación psicoanalítica de la memoria hace estallar la racionalidad del individuo reprimido. En tanto el conocimiento da lugar al reconocimiento, las prohibidas imágenes e impulsos de la niñez (y del pasado reciente e inmediato, agregaríamos) empiezan a decir la verdad que la razón niega (...) El pasado redescubierto proporciona niveles críticos (...)" (1968: 31-2), como ocurre cuando el sujeto valora su experiencia inmediata:

Jineteando mi nostalgia / buscaba el río de la infinita luna

Su hilera laberinto me cerró el paso

Perseguida persiguiendo / me obstiné por el agonizante rayo

me abismé de impaciencia / y recluté soledad

Retrocedí / afrenté mis propósitos

y recuperé aquel río (...)

Tributé codicia por mi terrosidad / y rescaté la esperanza

("Terrosidad", 79).

Por eso, la valoración de lo que ha sido desemboca en un gesto reivindicativo, en la medida en que la cura autobiográfica surte efecto y se avisora el presente con nuevos ojos, con ojos de "esperanza" como se exclama varias veces. De manera que la necesidad imperiosa por auto-afirmarse y por recuperar el pasado de niña y de mujer-amante se produce, no para clausurarse sobre tal hallazgo sino para abrirse a las diferentes tentativas que se ofrecen al sujeto dentro de una cotidianeidad revisitada; éste es el tematizador sobre el cual gravitan los poemas de la última sección, cuyo título es altamente significativo, "Ocurre", por cuanto sugiere precisamente la idea de un proceso en marcha, de algo que está sucediendo y no ha terminado y que el hablante lírico enarbola como la "vocación" a la que está destinado. Se trata de una búsqueda que apenas comienza y que se inicia ahí donde finaliza el poemario. Por eso, como la Penélope del mito griego, teje y desteje su experiencia vital para encontrar significación a su existencia: 


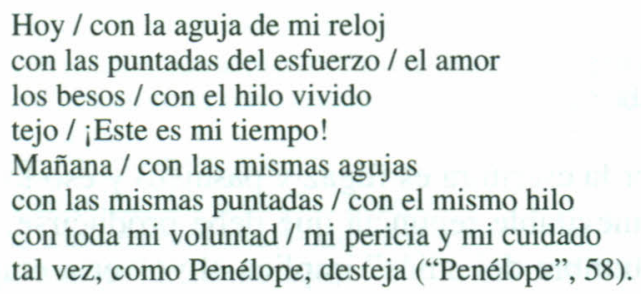

Sin embargo, a diferencia de la Penélope griega, el hablante lírico no está a la espera del amado ni subordina el ritmo de los recuerdos y la memoria de mujer a su ausencia. La Penélope que nos procura Marta Eugenia Rojas se halla en la imperiosa necesidad de comprenderse y si se encuentra en posición de espera tejiendo y destejiendo es para encontrar sentido a su destino. Por lo tanto, esta tejedora contemporánea supera la pasividad de la espera que convertía a su antecesora en un objeto del poder masculino, para desencadenar, con el motivo apuntado (la espera), una fuerza oculta e insondable que ensaya la liberación del sujeto femenino, pues como apunta Foucault en la emergencia de esa preocupación por sí mismo, mediante el ponerse en situación, el hombre podría no solo enfrentar las adversidades y las situaciones límites con el fin de encontrar un camino y planificar sus metas (1991: 67), de manera que el recorrido autobiográfico corresponde a un ejercicio de gimnasia ante pruebas reales y significativas (1991: 76); un ejercicio del cual sale el hablante lírico purificado y liberado de su alienación: Penélope toma conciencia de sí misma y empieza a construir su subjetividad con la certeza de que la búsqueda le augura nuevos derroteros y lo primero que debe procurar es salirse de ese refugio que significa estar atada a un pasado inmóvil. Eso es lo que el sujeto femenino ha comprendido al término de un periplo que conduce, en el mejor de los casos, al encuentro con su subjetividad.

\section{Notas}

1. Marta Eugenia Rojas Porras nació en 1950. Es profesora en la Escuela de Filología, Lingüística y Literatura de la Universidad de Costa Rica y ha ejercido la docencia tanto en la enseñanza secundaria como universitaria; en esta última destaca por su interés en el mejoramiento de la educación costarricense con la publicación de libros de texto para la lecto-escritura de la enseñanza primaria.

2. María Amoretti, en el artículo citado en la bibliografía, señala la presencia de este exilio interior en la constitución de textos autobiográficos femeninos, en donde el repliegue en la intimidad conlleva una doble necesidad: la de recogimiento y la de salirse de sí mismo. Tal parece, en palabras de Amoretti, que uno de los grandes problemas de esta asunción de una identidad femenina es la imposibilidad a crear esas relaciones con el otro y, en ese sentido, salirse de ese refugio interior para relacionarse con el mundo.

\section{Bibliografía}

Amoretti Hurtado, María. 1995. "La morada interior y sus espectros". Revista de Filología y Lingüística (Volumen extraordinario) I, enero-diciembre.

Aranguren, José Luis. 1989. "El ámbito de la intimidad”. En: Castilla del Pino (ed.), 17-24. 
Bajtin, Mijail. 1980. Estética de la creación verbal. México: Siglo Veintiuno Editores.

Blanch, Antonio. 1978. "Erotismo y pornografía". Razón y Fe. 197 (964): 477-86.

Castilla del Pino, Carlos (ed.). 1989. De la intimidad. Barcelona: Editorial Crítica.

Chen Sham, Jorge. 1994. "La súplica colectiva y la palabra redentora en 'Oración por Marilyn Monroe': un acercamiento pragmático". Revista de Filología y Lingüística. 20 (1): 25-34.

1996. "El erotismo en la narrativa autobiográfica española: el drama de identidad en Las edades de Lulú y en Rosa Mystica". Káñina, Revista de Artes y Letras. 20 (2): 35-44.

Foucault, Michel. 1991. Tecnologías del yo y otros textos afines. Barcelona: Ediciones Paidós Ibérica.

León Felipe. 1982. Ganarás la luz. Madrid: Ediciones Cátedra (edición de José Paulino).

Marcuse, Herbert. 1968. Eros y Civilización. Barcelona: Editorial Seix Barral, 5a. edición.

Navajas, Gonzalo. 1993. "Una estética para después del postmodernismo: la nostalgia asertiva y la reciente novela española". Revista de Occidente. (143): 105-30.

Peña-Marín, Cristina. 1989. "El discurso de la intimidad". En: Castilla del Pino (ed.), 77-96.

Rojas, Marta Eugenia. 1993. La sonrisa de Penélope y su costumbre del adiós. San José: Editorial de la Universidad de Costa Rica.

Starobinski, Jean. 1974. La relación crítica (Psicoanalísis y Literatura). Madrid: Taurus Ediciones.

Violi, Patrizia. 1987. "La intimidad de la ausencia: formas de la estructura epistolar". Revista de Occidente. (68): 87-99. 


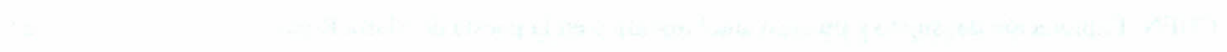

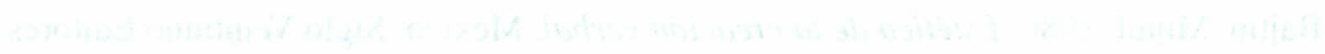

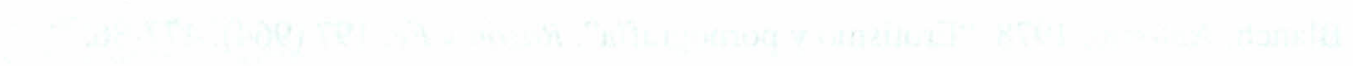

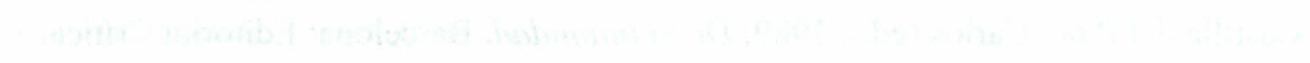

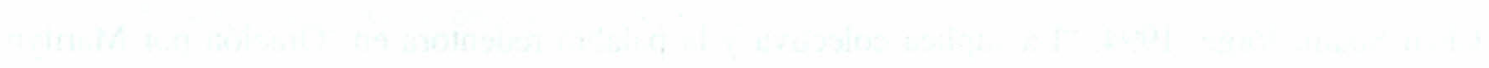

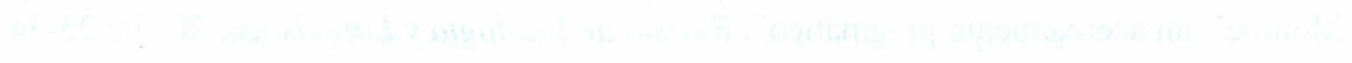

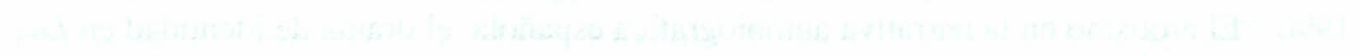

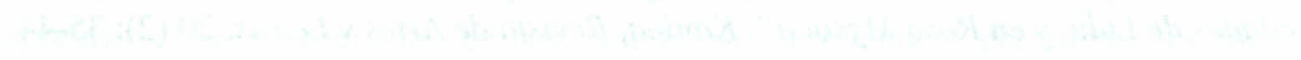

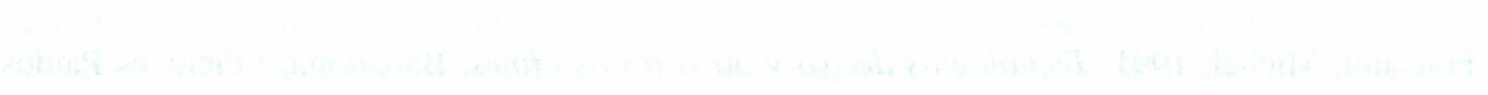

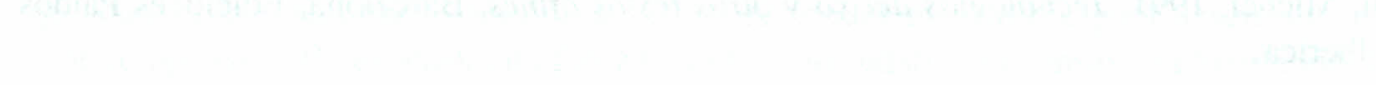

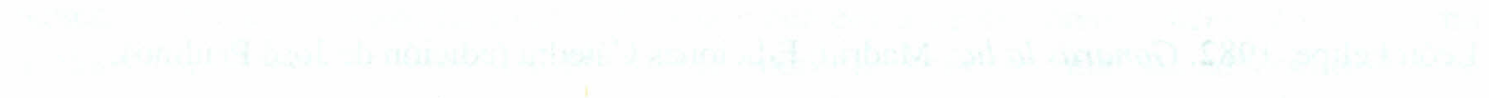

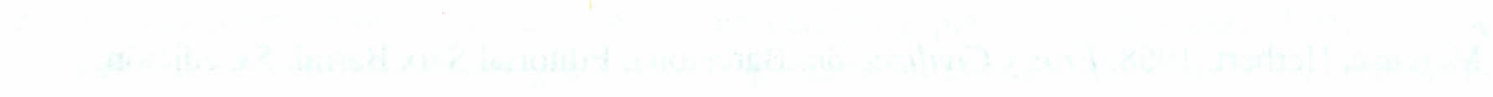

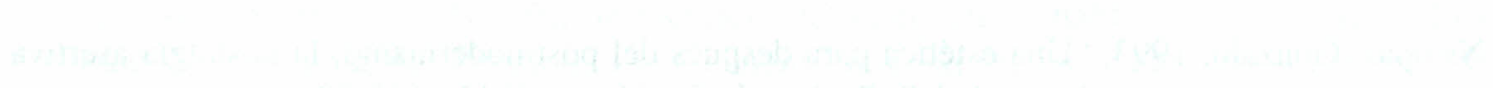
and

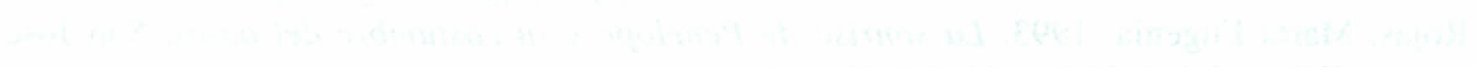

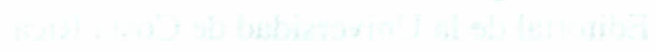

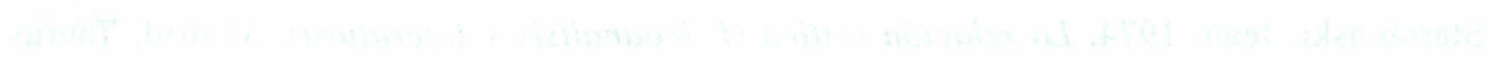

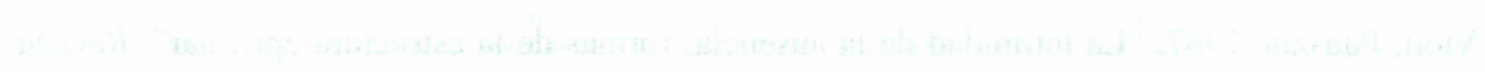

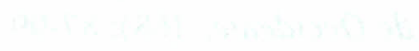

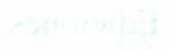

